\title{
Enabling topical and long-term anti-radical properties for percutaneous coronary intervention-related complications by incorporating TEMPOL into electrospun nanofibers
}

\author{
Jian $\mathrm{Lu}^{1 \dagger}$, Rui Wang ${ }^{2 \dagger}$, Li Shen ${ }^{2 \dagger}$, Jiasheng Yin ${ }^{2}$, Guilian Liu ${ }^{1}$, Han Chen ${ }^{2}$, Fei Xu ${ }^{2}$, Qilin Wu ${ }^{1}$, \\ Changhuai $\mathrm{Ye}^{1}$, Xiang Fei ${ }^{1^{*}}$, Junbo $\mathrm{Ge}^{2^{*}}$ and Meifang $\mathrm{Zhu}^{1^{*}}$
}

\begin{abstract}
Scavenging reactive oxygen species (ROS) by antioxidants has been demonstrated as the most effective strategy for preventing percutaneous coronary intervention (PCI)-related complications. However, topical and long-term delivery of ROS antioxidants to a specific vascular tissue is proven to be a great challenge. Herein, an ROS scavenger of 4hydroxy-2,2,6,6-tetramethylpiperidine- $N$-oxyl (TEMPOL) is incorporated into electrospun nanofibers with a tunable loading amount to achieve its topical applicability and long-term antiradical capability. Biological functions of such TEMPOL-loaded electrospun membranes are evaluated by cell proliferation, ROS-scavenging capability, monocyte adhesion, cell migration, inflammatory molecule secretion and mRNA expression in vitro. After optimizing the loading amount of TEMPOL, such an electrospun membrane presents a superior ROS-scavenging and anti-inflammation performance for both endothelial cells and macrophages. The expression of endothelial prothrombogenic molecules and the migration of vascular smooth muscle cells (VSMCs) are also effectively inhibited. Thus, it is bravely predicted that the topical use of such a TEMPOL-loaded electrospun system will be a promising pathway for the anti-restenosis therapy, especially when used as a novel coating on stent for long-term and topical delivery of antioxidant drugs.
\end{abstract}

Keywords: percutaneous coronary interventions, reactive oxygen species, TEMPOL, electrospinning, topical release

\section{INTRODUCTION}

Cardiovascular diseases (CVDs) remain the primary cause of morbidity and mortality globally [1], resulting in approximately 18 million CVD deaths annually [2]. Until now, percutaneous coronary interventions (PCI), including percutaneous transluminal coronary angioplasty (PTCA) and coronary stent implantation, have been widely applied for coronary artery revascularization as a non-surgical approach [3-5]. However, PCI-related complications, such as restenosis and stent thrombosis still occur at a fairly high rate and continue to limit the long-term success of the procedure. The excessive reactive oxygen species (ROS) production induced by PCI operations is recognized as a key role on the pathophysiological changes of vascular cells $[6,7]$. A high level of ROS would break the balance of the antioxidant defense system in human body, trigger the proliferation and migration of vascular smooth muscle cells (VSMCs) and promote monocyte/macrophage inflammation followed by endothelial dysfunction [8], thus resulting in the instent restenosis and/or thrombosis towards the stent failure [9]. Therefore, referring to such a mechanism, reducing the ROS level by using antioxidants should be the most feasible pathway in preventing PCI-related complications.

As one of the most common antioxidants, 4-hydroxy2,2,6,6-tetramethylpiperidine- $N$-oxyl (TEMPOL) features a "superoxide dismutase (SOD) mimetic" action [10], which can effectively scavenge and react with the $\mathrm{O}_{2}^{-}$to alleviate the harm of ROS. Specifically, as shown in Fig. S1, owing to its unique molecular structure, TEM-

\footnotetext{
${ }^{1}$ State Key Laboratory for Modification of Chemical Fibers and Polymer Materials, College of Materials Science and Engineering, International Joint Laboratory for Advanced Fiber and Low-dimension Materials, Donghua University, Shanghai 201620, China

${ }^{2}$ Department of Cardiology, Zhongshan Hospital, Fudan University, Shanghai Institute of Cardiovascular Diseases, Shanghai 200032, China

These authors contributed equally to this work.

* Corresponding authors (emails: xiangfei@dhu.edu.com (Fei X); ge.junbo2@zs-hospital.sh.cn (Ge J); zhumf@dhu.edu.cn (Zhu M))
} 
POL with a relatively small nitroxide molecule can transform $\mathrm{O}_{2}^{-}$to $\mathrm{H}_{2} \mathrm{O}_{2}$ by shuttling the nitroxide radical between the reduced hydroxylamine and the oxidized oxoammonium cation $[11,12]$. Such an encouraging catalytic mechanism is attributed to its "boat and chair" conformational changes $[11,13]$, showing a more effective performance than the counterpart of SOD. Moreover, benefiting from its function on reducing vascular matrix metalloproteases (MMPs), TEMPOL can diminish VSMC migration and vascular remodeling in injured arteries.

Despite above merits, the systemic administration of TEMPOL should be with a serious caution since some negatively inotropic effects might be caused, including the negative inotropic action, and inhibition of myocardial contractility [6]. Intuitively, topical application of TEMPOL through drug loading is deemed as an ideal approach, with the drug concentration released in an appropriate range and hopefully preserving a long-term anti-radical performance. To this end, we turn to prefer the electrospinning technologies based on following concerns: (i) with a mimicked natural extracellular matrix morphology, electrospun nanofibers have demonstrated as the attractive candidates for topical delivery of therapeutics [14-16]; (ii) encapsulating biologically active molecules (e.g., drugs [17-21], growth factors [22-26], RNAs [14,27]) into electrospun nanofibers is also pretty flexible and controllable in modulating cellular functions; (iii) in comparison with other encapsulating approaches such as hydrogel $[28,29]$, electrospun nanofibers have much higher specific surface area, and would facilitate cell proliferation as well as nutrient transport; (iv) more importantly, electrospinning technology can be perfectly combined with PCI therapy by mounting electrospun drug-loaded nanofibers onto bare metal stents, achieving the topical drug delivery $[18,30,31]$. Unfortunately, current efforts are mainly focusing on investigating the therapeutic mechanisms and clinical applications of TEMPOL $[32,33]$, whereas few attempts have been reported regarding their drug delivery materials. Until now, to the best of our knowledge, no reports concerning TEMPOL-loaded electrospun nanofibers have yet been proposed or demonstrated.

Herein, a first attempt was devoted to scavenging ROS by employing a TEMPOL-loaded $\operatorname{poly}(D, L$-lactic acid) (PDLLA) electrospun nanofibrous membranes as the topical release system. Through a coaxial electrospinning method, TEMPOL could be encapsulated into the PDLLA nanofibers and utilized to regulate the response of endothelial cells, smooth muscle cells and macrophage by adjusting its loading amount; and the shell layer of
PDLLA can regulate the release behavior of TEMPOL for a long-term performance. The proliferation of Human umbilical vein endothelial cells (HUVECs) on such membranes demonstrated that excessive TEMPOL loading has a certain cytotoxicity. With an optimized TEMPOL loading amount, such an electrospun membrane presented an effective anti-inflammatory performance by incubating macrophages and HUVECs under inflammatory stimulation, which were also demonstrated by the cell proliferation, corresponding gene expression with a real-time PCR, and enzyme-linked immunosorbent assay (ELISA). Moreover, cell migration stimulation of Human aortic smooth muscle cells (HASMCs) under inflammatory was also evaluated, showing an obvious inhibition by the released TEMPOL. And, its potential as a delivery vehicle for inhibiting intimal hyperplasia in PCI was further demonstrated.

\section{EXPERIMENTAL SECTION}

\section{Materials}

PDLLA (molecular weight $=88 \mathrm{kDa}$, polydispersity index $=1.76$ ) was purchased from Jinan Daigang Biomaterial Co. (China). TEMPOL and acetonitrile (high performance liquid chromatography, HPLC) were purchased from Aladdin Reagent Co. (China). Dichloromethane and methanol were purchased from Sinopharm Chemical Reagent Co. (China). Hexafluoroisopropanol (HFIP) was purchased from Shanghai Darui Finechem Co. (China). HUVECs and HASMCs were obtained from ScienCell Research Laboratories (San Diego, California, USA). Human THP-1 monocytes were kindly provided by Dr. Ruoshui Li from the Institute of Cardiovascular Disease, Shanghai, China. Endothelial cell medium (ECM) and smooth muscle cell medium (SMCM) with supplemented materials were purchased from ScienCell Research Laboratories (San Diego, California, USA). RPMI-1640 culture medium was obtained from Gibco Company (USA). Cell counting kit-8 (CCK-8) kit was purchased from Dojindo Laboratories (Japan).

\section{Preparation of TEMPOL-loaded PDLLA electrospun membranes}

The shell solution was prepared by dissolving $1.25 \mathrm{~g}$ PDLLA in $10 \mathrm{~mL}$ HFIP under stirring at room temperature for $12 \mathrm{~h}$; a series of core solutions were prepared by dissolving TEMPOL in deionized water and stirring at room temperature for over $0.5 \mathrm{~h}$ with their concentrations listed in Table 1. A coaxial electrospinning setup was used to prepare the TEMPOL-loaded PDLLA elec- 
Table 1 Compositions of TEMPOL-loaded PDLLA electrospun membranes with different loading amounts

\begin{tabular}{|c|c|c|c|c|c|c|}
\hline Samples & PDLLA (mg mL $\left.{ }^{-1}\right)$ & TEMPOL $\left(\mathrm{mg} \mathrm{mL}^{-1}\right)$ & Diameter (nm) & $\begin{array}{l}\text { Theoretical loading } \\
\text { amount (ng mg }{ }^{-1} \text { ) }\end{array}$ & $\begin{array}{l}\text { Actual loading } \\
\text { mount (ng mg }\end{array}$ & $\begin{array}{l}\text { Encapsulation } \\
\text { efficiency (\%) }\end{array}$ \\
\hline P-T-0 & 125 & - & $284.4 \pm 117.4$ & - & - & - \\
\hline P-T-0.1 & 125 & 1 & $415.2 \pm 228.1$ & 0.799 & $0.339 \pm 0.002$ & $42.5 \pm 0.3 \%$ \\
\hline P-T-0.2 & 125 & 2 & $421.1 \pm 245.7$ & 1.597 & $0.543 \pm 0.004$ & $33.9 \pm 0.3 \%$ \\
\hline P-T-0.5 & 125 & 5 & $371.8 \pm 222.2$ & 3.984 & $1.489 \pm 0.062$ & $37.4 \pm 1.6 \%$ \\
\hline P-T-1 & 125 & 10 & $369.6 \pm 192.1$ & 7.937 & $3.091 \pm 0.223$ & $38.9 \pm 2.8 \%$ \\
\hline P-T-2 & 125 & 20 & $362.8 \pm 236.5$ & 15.748 & $5.582 \pm 0.450$ & $35.6 \pm 2.9 \%$ \\
\hline P-T-5 & 125 & 50 & $239.0 \pm 155.3$ & 38.462 & $7.017 \pm 0.050$ & $18.2 \pm 0.1 \%$ \\
\hline
\end{tabular}

trospun membranes, as shown in Fig. 1. For the subsequent coaxial electrospinning, a coaxial spinneret with its internal diameters of 0.5 and $1.5 \mathrm{~mm}$ is used in this study. The shell and core solutions were pushed by syringe pump at a speed of 1 and $0.1 \mathrm{~mL} \mathrm{~h}^{-1}$, respectively, applied with a high voltage of $19.5 \mathrm{kV}$; and the collection distance was fixed to $15 \mathrm{~cm}$. As a control, the same shell and core solutions without TEMPOL were also applied to prepare the nanofibrous membranes. In this work, all the electrospun membranes were collected for $1 \mathrm{~h}$ on a rotating drum followed by a vacuum dry at $40^{\circ} \mathrm{C}$ for $12 \mathrm{~h}$ to remove residual solvent for further usage. And the samples prepared by varying concentrations of the TEMPOL solutions $\left(0,1,2,510,20\right.$ and $\left.50 \mathrm{mg} \mathrm{mL}^{-1}\right)$ were named as P-T-0, P-T-0.1, P-T-0.2, P-T-0.5, P-T-1, P-T-2 and P$\mathrm{T}-5$, respectively.

\section{Characterizations}

Scanning electron microscopy (SEM) images were obtained with a Hitachi SU8010 (Japan). Transmission electron microscopy (TEM) images were obtained with a JEM-2100 (Japan). The electron paramagnetic resonance (EPR) spectra were recorded at room temperature in a Bruker A300 (Germany) spectrometer operating at $9.85 \mathrm{GHz}$ with $100 \mathrm{kHz}$ magnetic field modulation. The spectra were collected with the following parameters: sweep width $200 \mathrm{G}$; microwave power $19.23 \mathrm{~mW}$; receiver gain $2.00 \times 10^{1}$; time constant $10.24 \mathrm{~ms}$; conversion time $49.00 \mathrm{~ms}$. High performance liquid chromatography (HPLC, LC 2050, China) analyses were carried out with a mobile phase comprised of acetonitrile and water (95/5, $v / v)$ to determine the actual loading amount of TEMPOL in the as-electrospun membranes. For the TEMPOL release experiment, the mobile phase was changed and comprised of acetonitrile and water $(40 / 60, v / v)$. More detailed information and statement can be found in the Supplementary information. All samples were run in triplicate.

\section{In vitro release behaviors of TEMPOL-loaded PDLLA nanofibers}

To evaluate the release behavior of TEMPOL from the nanofibers, membranes loaded with different amounts of TEMPOL were immersed with $4 \mathrm{~mL}$ phosphate-buffered saline (PBS, $\mathrm{pH} 7.4$ ) at $37^{\circ} \mathrm{C}$ for TEMPOL release; at certain time intervals, $1 \mathrm{~mL}$ of the above solution was then taken and used for the following HPLC analysis with a mobile phase consisting of acetonitrile and water (40/ $60, v / v)$. And, an equal volume of fresh PBS was added into the stock solution for following release incubation. The release percentage was calculated with Equations (1) and (2) as follows:

$M_{t}=M_{1}+M_{2}+\ldots+4 M_{x}$,

$Q_{t}=\frac{M_{t}}{M_{\infty}} \times 100 \%$,

where $M_{t}$ is the cumulative amount of drug released from the electrospun membrane at predetermined time $t$, $M_{x}(x=1,2,3 \ldots)$ is the amount of drug in $1.0 \mathrm{~mL}$ PBS at predetermined time, and $M_{\infty}$ refers to the total amount of drug released from the electrospun membrane which was set as the cumulative amount of drug at day $31, Q_{t}$ is the release percentage at predetermined time $t$.

\section{In vitro performance}

\section{Cell culture}

Each sample was cut into a complete piece and folded to match the size of culture plate well with the same density of $0.6316-0.7895 \mathrm{mg} \mathrm{cm}^{-2}$. All the samples with the culture plate were sterilized under ultraviolet light for $2 \mathrm{~h}$. Stainless steel rings were used to prevent the membranes from floating. For cell seeding, electrospun membranes were placed in 24-well or 12-well plates, and cells were 

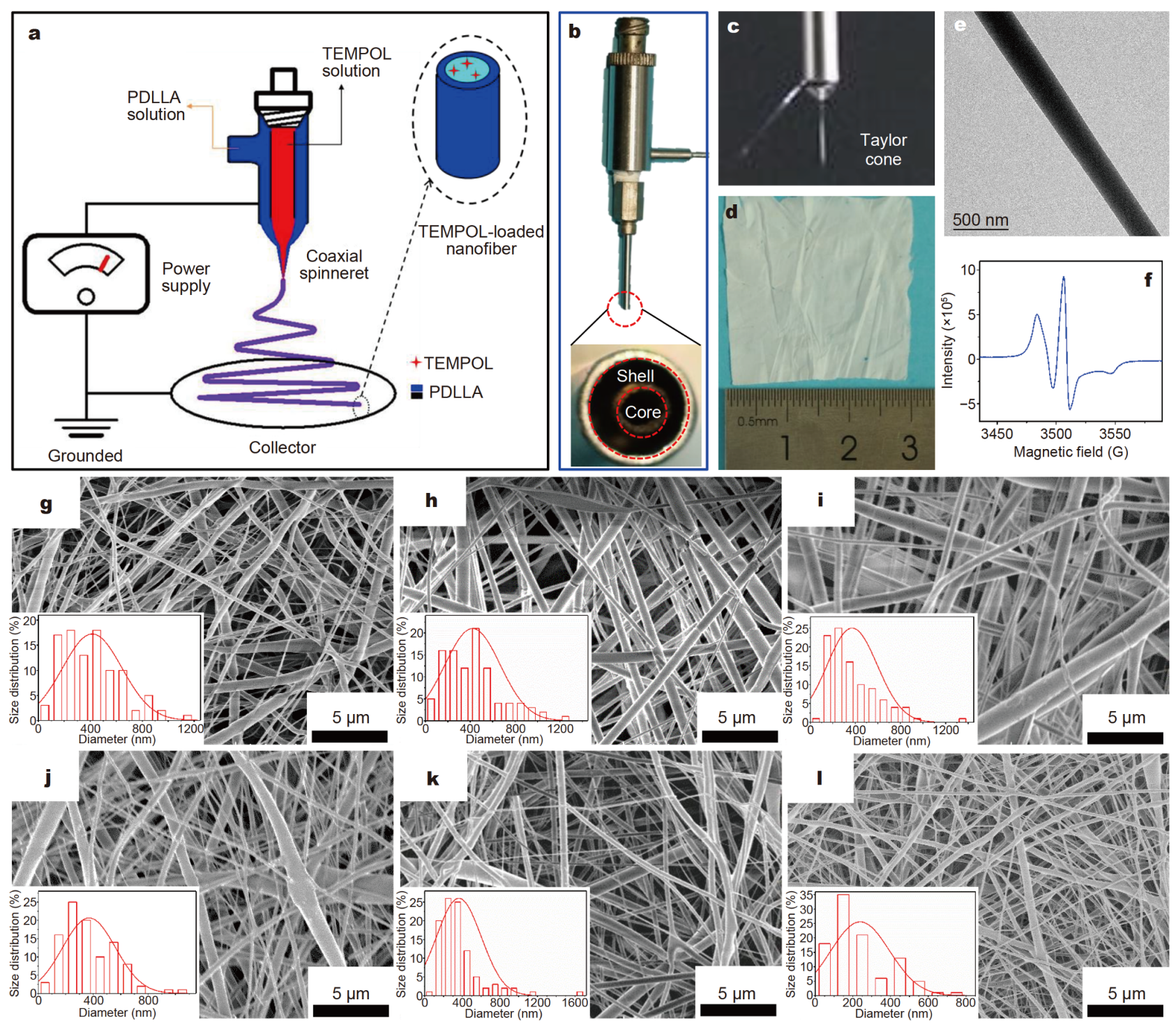

Figure 1 The coaxial electrospinning apparatus and the corresponding electrospinning process. (a) Schematic illustration for the preparation of TEMPOL-loaded PDLLA electrospun membranes; (b) the coaxial spinneret; (c) a Taylor cone observed at $10 \mathrm{kV}$; (d) a digital photo of the obtained TEMPOL-loaded PDLLA membrane; (e) a representative TEM image of one as-electrospun nanofiber (P-T-1); (f) EPR spectrum of the P-T-1. (g-1) SEM images of the as-fabricated electrospun membranes by varying the concentration of core spinning TEMPOL solutions: (g) P-T-0.1, (h) P-T-0.2, (i) P-T-0.5, (j) P-T-1, (k) P-T-2 and (l) P-T-5, respectively.

seeded upon membranes with a certain concentration. Cells were cultured at $37^{\circ} \mathrm{C} / 5 \% \mathrm{CO}_{2}$ to allow for cell adhesion and equilibrium of cell spreading.

HUVECs were cultured in ECM with 5\% fetal bovine serum (FBS), 1\% endothelial cell growth supplement (ECGS) and $1 \%$ penicillin-streptomycin as supplemented materials. HASMCs were maintained in SMCM supplemented with $2 \%$ FBS, $1 \%$ smooth muscle cell growth supplement (SMCGS). THP-1 monocytes were cultured in RPMI-1640 medium containing 10\% FBS and 1\% pe- nicillin-streptomycin. Then the cells were seeded in 12well or 24-well culture plates and incubated with specific medium at $37^{\circ} \mathrm{C}$.

\section{Cell proliferation assay}

For the cell viability study, $500 \mu \mathrm{L}$ of $2 \times 10^{5}$ HUVECs was incubated on the electrospun nanofibrous membranes in 24-well culture plates, and quantified on day 1,3 and 5 by CCK- 8 assay. The measurement was performed over four biological replicates. 


\section{Cell spreading morphology}

The spreading of HUVECs on the electrospun membranes was also examined by using SEM, live cells staining and immunofluorescence staining through fluorescence microscope (Olympus, Japan). For SEM analysis, samples were fixed in $2.5 \%(v / v)$ glutaraldehyde for $2 \mathrm{~h}$, dehydrated using graded ethanol, and then critical-point-dried before observation. Cell Tracker Green CMFDA (Yeason, China) was used for live cell staining. Stained cells were imaged by fluorescence microscope. Image J was then used to count cell numbers of 4 independent views per well. Von Willebrand factor antibody (vWF, 1:100, Abcam, UK) was used as the endothelial marker, and 4,6-diamidino-2-phenylindole (DAPI, Weiao Biotech; China) was used for cell nuclei staining. The marked cells were imaged by fluorescence microscope.

\section{ROS-scavenging capability}

ROS production was evaluated using dihydroethidium (DHE, Beyotime Biotechnology, China) stain. HUVECs and THP-1 cells were seeded under electrospun membranes for three days in complete medium before stimulating with $0.1 \mathrm{mmol} \mathrm{L}^{-1} \mathrm{H}_{2} \mathrm{O}_{2}$ (Weiao Biotech, China) for $6 \mathrm{~h}$. Electrospun membranes and medium were removed, $10 \mu \mathrm{mol} \mathrm{L}^{-1}$ DHE was added and cells were incubated for $1 \mathrm{~h}$. DHE was discarded and cells were washed three times with cold PBS. Stained cells were imaged by fluorescence microscope. Image $J$ was then used to count cell numbers of 4 independent views per well.

\section{Monocyte adhesion}

THP-1 cells were incubated with $20 \mathrm{mmol} \mathrm{L}^{-1}$ Calcein AM (KeyGEN BioTech, China) for $20 \mathrm{~min}$, then washed twice with PBS. HUVECs were cultured on the membranes for three days to reach over $80 \%$ confluence before cells were stimulated by $10 \mathrm{ng} \mathrm{mL}^{-1}$ tumor necrosis factor- $\alpha$ (TNF $\alpha$, PeproTech, USA) for $2 \mathrm{~h}$. Thereafter, $4 \times 10^{4}$ Calcein AM-labelled THP-1 cells were incubated with HUVECs at $37^{\circ} \mathrm{C}$ for $1 \mathrm{~h}$ on an orbital incubator. Nonadherent cells were removed by washing for three times with PBS. Fluorescence microscope was used for photograph of cells. Image $\mathrm{J}$ was then used to count cell numbers of 5 independent views per well.

\section{Cell migration}

HASMCs were cultured on 12 -well plates to $90 \%-95 \%$ confluence in SMCM, and serum deprived for $12 \mathrm{~h}$. A straight scratch-wound was made on the cellular layer using a sterilized $200-\mu \mathrm{L}$ pipette tip. Cell Tracker Green CMFDA was used to label HASMCs. Electrospun membranes (i.e., P-T-0 and P-T-1) were placed on top of HASMCs. Platelet-derived growth factor subunit B (PDGF-BB, PeproTech, USA, $20 \mathrm{ng} \mathrm{mL}^{-1}$ ) was added in culture medium and maintained for $24 \mathrm{~h}$. Cell migration was followed by fluorescence microscopy at indicated time points (i.e., 0,16 and $24 \mathrm{~h}$, respectively) up to wound healing closure. Image J was used to count cell numbers of 5 independent views per well.

\section{ELISA}

THP-1 cells were seeded on electrospun nanofibrous membranes $\left(0.6316-0.7895 \mathrm{mg} \mathrm{cm}^{-2}\right)$ at a density of $8 \times 10^{4}$ cells/well in 12-well plates. Phorbol 12-myristate 13-actate (PMA, $100 \mathrm{ng} \mathrm{mL}^{-1}$; Sigma-Aldrich, USA) was added in the culture medium and maintained for three days for the differentiation of THP-1 cells to $\mathrm{M}_{0}$ type macrophages. Then cells were stimulated by lipopolysaccharide (LPS, $200 \mathrm{ng} \mathrm{mL}^{-1}$, Sigma-Aldrich, USA) for $2 \mathrm{~h}$. The cell-free culture supernatants were collected for ELISA tests. Cells were harvested for protein concentration measurement using bicinchoninic acid assay kit (BCA; Weiao Biotech, China). Cytokine secretions (interleukin-1 $\beta$ (IL-1 $\beta$ ), interleukin-6 (IL-6), interleukin-18 (IL-18), TNF $\alpha$ ) in supernatants of LPS-stimulated cells were measured using high sensitivity ELISA kit (MultiSciences, China). Procedures were accomplished according to manufacturer's instructions. The measurement was performed twice from three biological replicates.

\section{Gene expression by real-time PCR}

The total RNA was isolated using an adsorption columnbased extraction kit (Tiangen Biotech, China) according to the manufacture's protocol. Complementary DNA (cDNA) was synthesized from isolated RNA with PrimeScript RT Master Mix (Takara, Japan). qRT-PCR was performed in triplicates using TB Green Premix Ex Taq II (Takara, Japan) with a CFX96 real-time PCR system and CFX Manager Software (Bio-Rad Laboratories GmbH, Munich, Germany). Glyceraldehyde-3-phosphate dehydrogenase (GAPDH) was used as reference gene. The relative messenger RNA expressions were calculated using comparative cycle threshold (CT) value method $(\Delta C(t)$ and $\Delta \Delta C(t))$. The measurement was performed twice from three biological replicates. qRT-PCR primers were as follows:

IL-1 $\beta$ : Forward-5'-CCACAGACCTTCCAGGAGAATG-3' and Reverse-5'-GTGCAGTTCAGTGATCGTACAGG-3'; IL-6: Forward-5'-AGACAGCCACTCACCTCTTCAG-3' 
and Reverse-5'-TTCTGCCAGTGCCTCTTTGCTG-3'; IL-18: Forward-5'-GATAGCCAGCCTAGAGGTATGG3' and Reverse-5'-CCTTGATGTTATCAGGAGGATTCA-3';

TNFa: Forward-5'-CTCTTCTGCCTGCTGCACTTTG-3' and Reverse-5'-CCTTGATGTTATCAGGAGGATTCA-3'; VCAM-1: forward-5'-GATTCTGTGCCCACAGTAAGG C-3' and Reverse-5'-TGGTCACAGAGCCACCTTCTTG3';

Tissue factor (TF): Forward-5'-CAGAGTTCACACCTT ACCTGGAG-3' and Reverse-5'-GTTGTTCCTTCTGAC TAAAGTCCG-3';

E-selectin: Forward-5'-GGACACCACAAATCCCAGTC TG-3' and Reverse-5'-TCGCAGGAGAACTCACAACTG G-3';

Plasminogen activator inhibitor-1(PAI-1): Forward-5'GGACACCACAAATCCCAGTCTG-3' and Reverse-5'TCGCAGGAGAACTCACAACTGG-3';

GAPDH: Forward-5'-GTCTCCTCTGACTTCAACAGC G-3' and Reverse-5'-ACCACCCTGTTGCTGTAGCCA A-3'.

\section{Statistical analysis}

All quantitative data are presented as mean \pm standard deviation (SD). Statistical difference between groups was analyzed by unpaired t-test and one-way ANOVA test. $p$ value 0.05 was considered to be statistically significant between groups.

\section{RESULTS AND DISCUSSION}

\section{Characteristics of the TEMPOL-loaded PDLLA electrospun membranes}

In this study, a coaxial electrospinning process was used to incorporate TEMPOL into nanofibers (Fig. 1a-d). PDLLA was used here to form the shell layer of the coreshell nanofibers due to its good biocompatibility and electro-spinnability (Fig. 1a). Fabricated as such, TEMPOL can be effectively incorporated into the electrospun PDLLA nanofibers (Fig. 1d). Here, it should be noted that the as-electrospun nanofibers in such a coaxial electrospinning system presented a fuzzy core-shell structure with no clear boundary, which is mainly due to the good compatibility between the solutions of the shell layer and the core layer (Fig. 1e and Fig. S2). As a powerful technique for studying the motion of nitroxyl radicals, EPR spectra were further utilized to study the EPR signals of the as-obtained membranes. As shown in Fig. 1f, a characteristic triplet signal of the nitroxyl radical was observed clearly, confirming the presence of TEMPOL radicals in the electrospun membranes [34,35].

Moreover, the loading amount of TEMPOL can be adjusted by simply varying the concentration of TEMPOL solution (i.e., the core layer spinning solution). The surface morphology of the as-electrospun membranes with different loading amounts of TEMPOL was demonstrated by SEM (Fig. S3 and Fig. 1g-1). As shown in Fig. 1g-l, all fibers are smooth and randomly oriented with no visible beads-on-a-string or spindles-on-a-string phenomena, yet with their diameters uneven. Such a size unevenness might be due to the complexity and compatibility of dual spinning solutions in such a coaxial electrospinning system, thus affecting the uniform formation of the nanofibers. As the inner spinning TEMPOL concentration increased from 1 to $50 \mathrm{mg} \mathrm{mL}^{-1}$, the electrospun nanofibers only displayed a slight change in their diameters, i.e., $(415.2 \pm 228.1) \mathrm{nm}(\mathrm{P}-\mathrm{T}-0.1),(421.1 \pm 245.7) \mathrm{nm}(\mathrm{P}-\mathrm{T}$ $0.2),(371.8 \pm 222.3) \mathrm{nm}(\mathrm{P}-\mathrm{T}-0.5),(369.6 \pm 192.1) \mathrm{nm}(\mathrm{P}-\mathrm{T}-$ $1),(362.8 \pm 236.5) \mathrm{nm}(\mathrm{P}-\mathrm{T}-2)$ and $(239.0 \pm 155.3) \mathrm{nm}(\mathrm{P}-$ $\mathrm{T}-5$ ), respectively (Table 1 ).

\section{In vitro release of TEMPOL}

The actual loading amounts of TEMPOL in such PDLLA nanofibers were further determined by HPLC with their calculated results recorded in Table 1. Obviously, the actual loading amount of TEMPOL is increased with increasing spinning solution concentration, while their encapsulation efficiency presents a significant decrease from $\sim 42.5 \%$ for P-T-0.1 to $\sim 18.2 \%$ for P-T-5. Such a declined encapsulation efficiency can be attributed to that higher concentrations of TEMPOL have more tendency to migrate to the surface or near the surface of nanofibers during the electrospinning process, thus leading to a certain loss during the subsequent processing procedures, which is similar to some previous reports [36,37].

To study the releasing behaviors, in vitro release measurements were conducted on such TEMPOL-loaded PDLLA electrospun membranes which were monitored by HPLC for 19 days (Fig. 2). As shown in Fig. 2a, it was found that the release behavior of TEMPOL for all the samples experienced two stages: (i) the initial burst release in the first day with a release percentage of $40 \%$ to $70 \%$, and (ii) the continuous slow release to a platform for the following 18 days. The initial burst release is mainly attributed to the diffusion of TEMPOL on the surface or under very near the surface of fibers [38]. Comparably, the releasing rates of P-T- 0.5 and P-T- 1 in $24 \mathrm{~h}$ were obvious slower than others; it is assumed that appropriate TEMPOL loading in such electrospun membranes can also preserve a low TEMPOL release rate that are pre- 

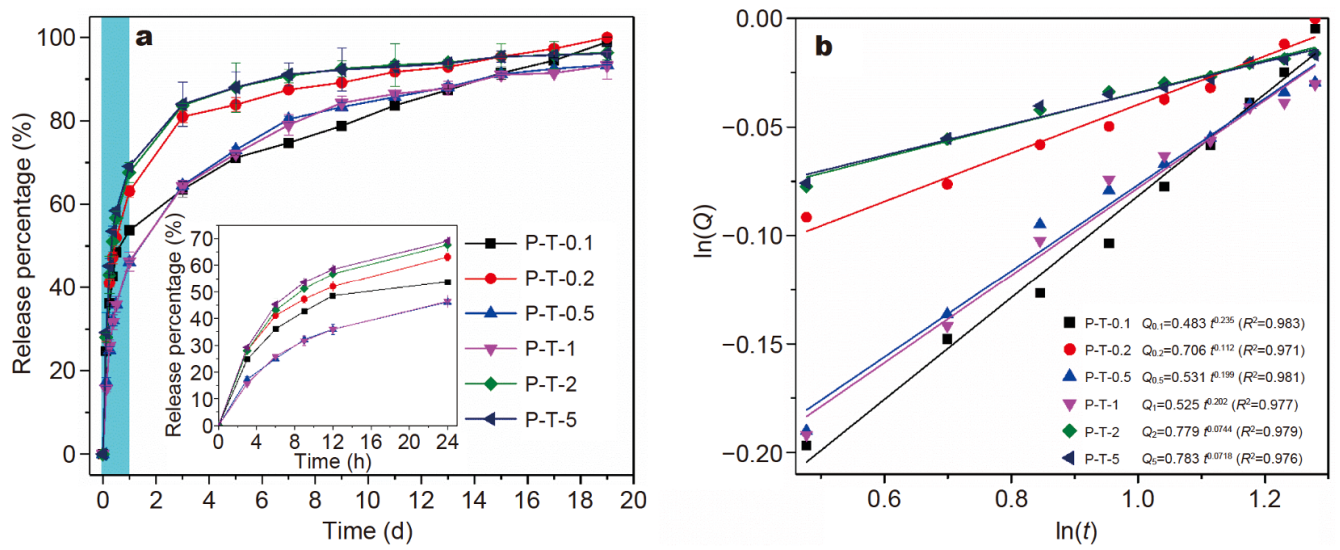

Figure 2 In vitro release curves. Raw release data are given for (a) the entire 19-day experiment with the inset showing the burst release in the 1st day; (b) Korsmeyer-Peppas plots for the TEMPOL release from the TEMPOL-loaded PDLLA electrospun membranes.

ferable for a long-term scavenge of ROS. To further study the releasing mechanism, the data were further fitted according to the zero-order model, one-order model, Higuchi model and Korsmeyer-Peppas model, respectively $[39,40]$, and analyzed with the Equations (3-6) as follows:

zero-order model:

$Q=k t$,

one-order model:

$\ln (1-Q)=-k t$,

Higuchi model:

$Q=k t^{1 / 2}$,

Korsmeyer-Peppas model:

$Q=k t^{n}$,

where $Q$ is the release percentage, $k$ is the rate constant, and $n$ in Korsmeyer-Peppas model is an exponent which sheds some insights on the drug release mechanism. As calculated and shown in Fig. 2b, Figs S4 and S5, and Table S1, the fitting of TEMPOL release kinetics presented a preferable match to the Korsmeyer-Peppas model (Table S1); rather than the other ones (i.e., Higuchi model, zero-order model and one-order model). Additionally, all samples have their $n$ values lower than 0.45 , corresponding to a Fickian diffusion mechanism $[39,41,42]$, which is also in consistent with above releasing behaviors.

\section{Adhesion and proliferation behavior of HUVEC on TEMPOL-loaded PDLLA electrospun membranes}

To investigate the cytotoxicity of excessive TEMPOL on HUVECs, we investigated the cell proliferation behavior

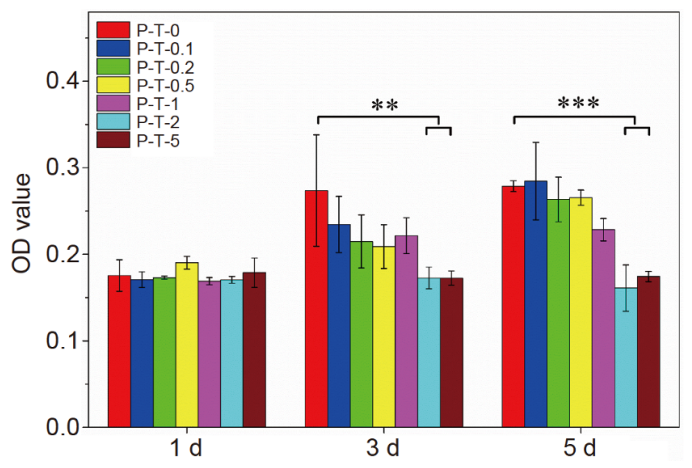

Figure 3 CCK- 8 results of HUVECs cultured on the TEMPOL-loaded PDLLA electrospun membranes with different loading amounts for 1,3 and 5 days, respectively. Data are presented as means $\pm \mathrm{SD}\left(n=4,{ }^{* *} p<\right.$ $\left.0.01, \quad{ }^{* * *} p<0.001\right)$.

on the TEMPOL-loaded electrospun membranes with different loading amounts by CCK- 8 assay. As shown in Fig. 3 and Fig. S6, it can be found that the sample with a higher TEMPOL loading (i.e., P-T-2 and P-T-5) presented a certain cytotoxicity; the cell proliferation was therefore inhibited in all the incubation experiments from 1 to 5 days.

Furthermore, living HUVECs on the electrospun membranes were stained and detected by Cell Tracker Green CMFDA; and the results was shown in Fig. 4. After an incubation for three days, all the samples present a good biocompatibility, and an obvious cell proliferation can be observed on P-T-1 (Fig. 4b) with an equivalent cell counts to the control sample of P-T-0 (Fig. 4a). In comparison, the cell counts on the sample of P-T-5 was much lower than the other two counterparts (Fig. 4c, d), exhibiting a significant inhibition effect caused by the 

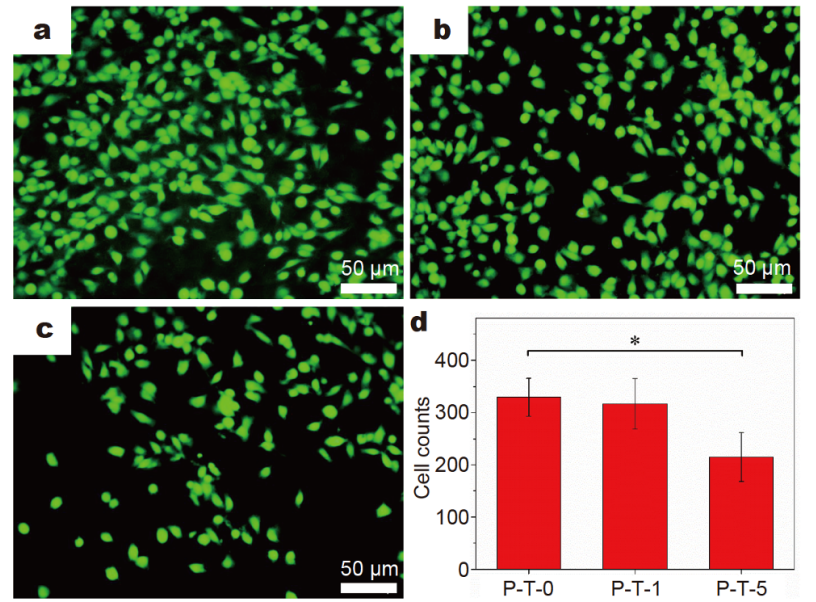

Figure 4 Live cell staining of HUVECs by Cell tracker green CMFDA. The HUVECs were incubated for three days on the electrospun membranes of (a) P-T-0, (b) P-T-1, and (c) P-T-5, respectively; and (d) their cell counts. Data are presented as means $\pm \mathrm{SD}(n=4, \stackrel{*}{p}<0.05)$. excessive TEMPOL; such a result is also in consistence with the result of CCK-8 assay (Fig. 3).

Additionally, SEM and fluorescence microscope were further used to study the cell morphology of HUVECs after a 3-day incubation on the P-T-0, P-T-1 and P-T-5 samples. As observed by SEM (Fig. 5a-c), the HUVECs on the three samples spread over the entire region of the membranes with cobblestone-like morphologies. Besides, the P-T-0 and P-T-1 membranes exhibited excellent cellular biocompatibility for HUVECs growth in comparison with the P-T-5 membrane. The endothelial expression of vWF marker was confirmed in cells on day 3. From the fluorescence micrographs (Fig. 5a1-c3), it can be seen that HUVECs on the P-T-1 and P-T-5 samples exhibited positive vWF expression, which is in consistence with their typical endothelial phenotype [27]. Furthermore, the results displayed that the electrospun membranes loaded with appropriate TEMPOL (i.e., P-T-1
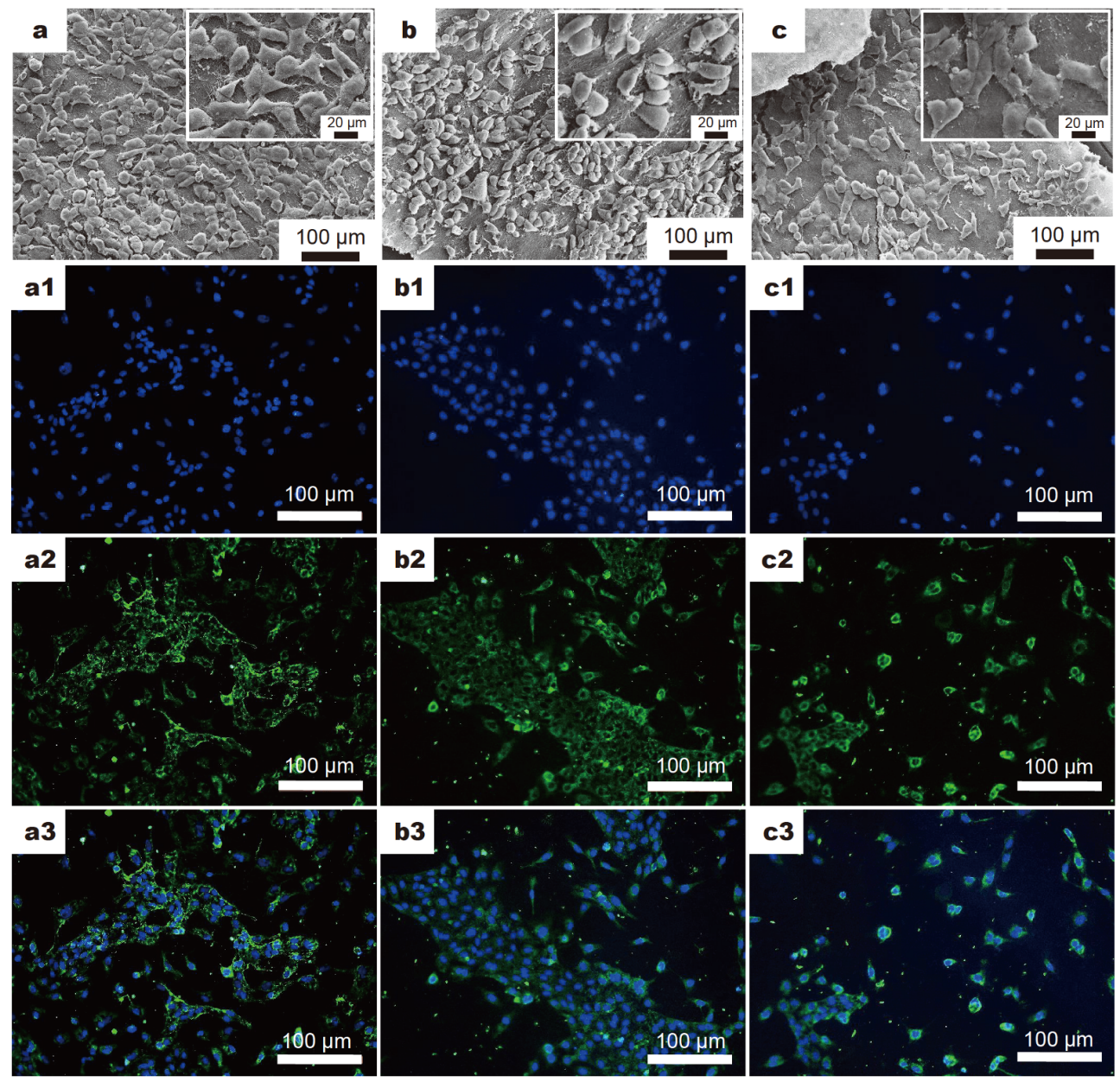

Figure 5 SEM and fluorescence microscope images of the HUVECs incubated for three days on the electrospun membranes of (a) P-T-0, (b) P-T-1, and (c) P-T-5, respectively. Green: vWF, blue: DAPI. 
sample) could well maintain the shape and phenotype of HUVECs, suggesting an excellent performance in keeping the cell activities.

\section{ROS-scavenging and anti-inflammation performance}

Previous reports have well demonstrated that ROS produced by macrophages has multiple adverse impact on vascular cells (e.g., the dysfunction and activation of endothelial cells and VSMCs) [43,44], and eventually result in the restenosis as mentioned in the introduction section. Consequently, it is highly desired to know whether these TEMPOL-loaded PDLLA membranes can effectively inhibit the ROS production. To this end, THP-1derived macrophages pre-incubated with the electrospun membranes for three days were utilized, and $\mathrm{H}_{2} \mathrm{O}_{2}$ $\left(0.1 \mathrm{mmol} \mathrm{L}^{-1}\right)$ was used as a stimulator to trigger the ROS production in THP-1 cells which can be probed by a fluorescent dye of DHE. ROS level was significantly elevated after $\mathrm{H}_{2} \mathrm{O}_{2}$ stimulation of THP-1-derived macrophages with P-T-0 (Fig. 6a, b). In comparison, DHE fluorescent signals of the macrophages with P-T-1 sample presented an obvious attenuation of ROS production (Fig. 6c), exhibiting an effective ROS scavenging performance (Fig. 6d).

Moreover, the inflammatory responses of THP-1 cells on such membranes were further investigated. As shown in Fig. 7, the mRNA expression and secretion of proinflammatory cytokines on the P-T-1 samples revealed a remarkable anti-inflammatory effect in comparison with
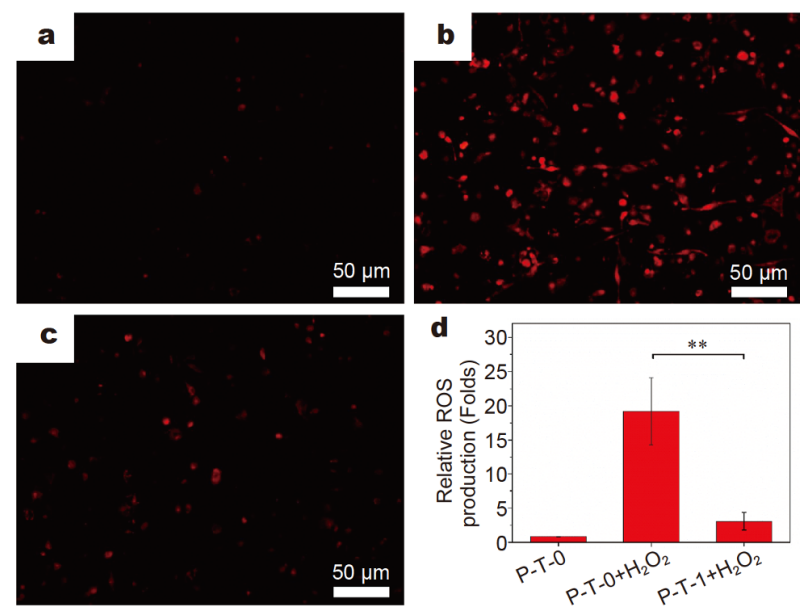

Figure 6 DHE staining of ROS in THP-1 cells. THP-1 cells were seeded on samples for three days before a $\mathrm{H}_{2} \mathrm{O}_{2}\left(0.1 \mathrm{mmol} \mathrm{L}^{-1}\right)$ stimulation for $6 \mathrm{~h}$. (a) DHE-labelled THP-1 cells cultured on the (a, b) P-T-0 sample (a) without $\mathrm{H}_{2} \mathrm{O}_{2}$ and (b) with $\mathrm{H}_{2} \mathrm{O}_{2}$ stimulation, and on the (c) P-T-1 sample with $\mathrm{H}_{2} \mathrm{O}_{2}$ stimulation. (d) Quantitative analysis of integrated optical density. Data are presented as means $\pm \mathrm{SD}(n=4, \stackrel{* *}{p} p<0.01)$. the P-T- 0 counterpart, including the TNFa, IL- $1 \beta$, IL- 6 and IL-18. Notably, P-T-5 sample with much higher TEMPOL loading did not present a better anti-inflammation performance than P-T-1 sample, with the main reason that overwhelming scavenging of ROS would be detrimental because the existence of oxidants also have some positive functions, e.g., homeostatic and well-calibrated signaling [45]. Based on these results, it has demonstrated that such electrospun membranes with an appropriate TEMPOL loading can effectively counteract induced oxidative stress and reduce secretion of inflammatory cytokines in macrophages; which is consistent with previous reports that conducted by direct administration of TEMPOL [46].

\section{Anti-inflammation and anti-monocytes adhesion of HUVECs on TEMPOL-loaded PDLLA membranes}

It has well demonstrated that the vascular endothelium is vulnerable to the tissue damage by oxidants during intravascular interventions [9], thus leading to dysfunctional endothelium followed by the activation of the endothelium cells and increasing of monocyte adhesion from blood circulation. Such a pathological evolution is assumed as a key inducement in pathogenesis of in-stent restenosis $[47,48]$. Furthermore, vascular injury would trigger the expression of prothrombogenic molecules in dysfunctional endothelium, which is a crucial factor of early in-stent thrombosis resulting in stent failure [49]. To study the effects of these TEMPOL-loaded PDLLA membranes on the above negative consequences caused by dysfunction of endothelium cells, TNFa was used as a stimulator to trigger the dysfunction of HUVECs preincubated with the electrospun membranes.

As shown in Fig. 8, the results have demonstrated that TNF $\alpha$ stimulation would enhance mRNA expression of cell adhesion molecules on the P-T-0 sample (i.e., E-Selectin and VCAM-1 in Fig. 8a, b). Such an mRNA expression presented a much lower level on TEMPOLloaded PDLLA samples, especially for the P-T-1 and P-T2 samples (Fig. 8a, b). Monocytes adhesion tests were also performed to further demonstrate their anti-inflammatory effect in HUVECs (Fig. 9). Similarly, TEMPOL-loaded PDLLA membranes have significantly attenuated the adhesion of THP-1 monocytes to the TNFa-stimulated HUVECs by using the P-T-1 sample (Fig. 9).

Moreover, the inhibition effect on expression of prothrombogenic factors of endothelial cells was further studied. As shown in Fig. 8c and d, an increased mRNA expression of prothrombogenic factors (TF, Plasminogen 

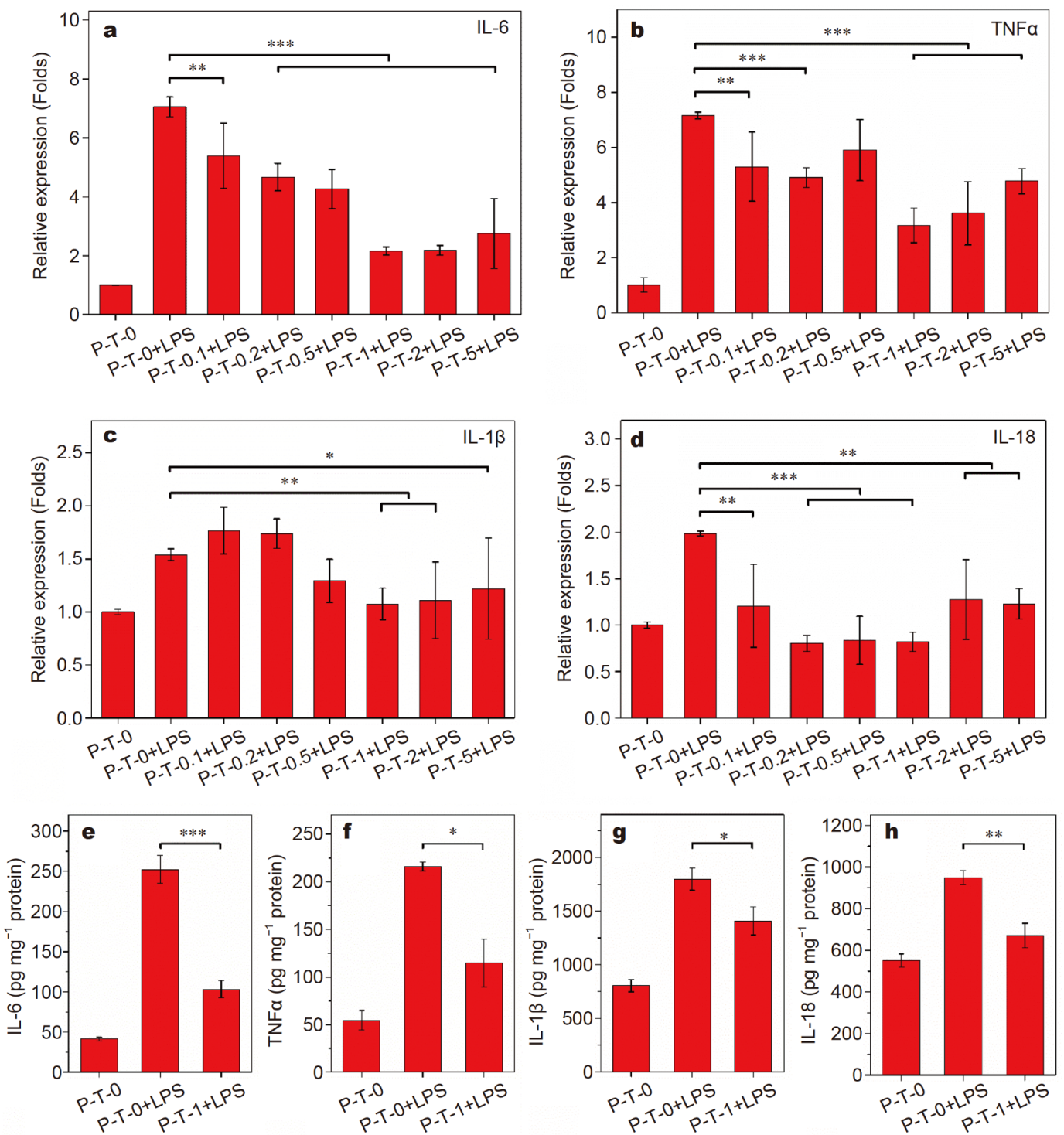

Figure 7 Inhibition of inflammation in THP-1 cells on the TEMPOL-loaded PDLLA electrospun membranes. THP-1 cells were incubated with P-T-1 samples for three days followed by a stimulation of LPS for $2 \mathrm{~h}$. Expression of (a) IL-6, (b) TNFa, (c) IL-1 $\beta$ and (d) IL-18 was detected by qRT-PCR, and the protein level of (e) IL-6, (f) TNFa, (g) IL- $1 \beta$ and (g) IL-18 was detected by ELISA of THP-1 cells cultured on the different samples. Data are presented as means \pm SD $\left(n=3,{ }^{*} p<0.05,{ }^{* *} p<0.01\right.$ and $\left.{ }^{* * *} p<0.001\right)$.

Activator Inhibitor-1 (PAI-1)) was observed in HUVECs after a stimulation by TNFa for $2 \mathrm{~h}$. Only P-T-1 and P-T-2 displayed a significant inhibition on mRNA expression of PAI-1. All samples except the P-T-0.5 exhibited significant inhibition on mRNA expression of TF. We have also performed a detailed analysis of biological response of HUVECs to these electrospun membranes under inflammatory conditions, hopefully to provide more information about potential application in preventing or treating endothelial dysfunction after PCI procedure.

\section{HASMCs migration under TEMPOL-loaded PDLLA} electrospun membranes

Migration of activated VSMCs often leads to the pathological changes of vessel including restenosis after PCI [50]. Vascular injury could induce VSMC migration through various cytokines secreted by inflammatory cells, platelets and VSMCs. To study the migration behavior of VSMCs on such electrospun membranes, we firstly utilized the most potent stimulant of PDGF-BB to stimulate the VSMCs followed by an incubation on the membranes 

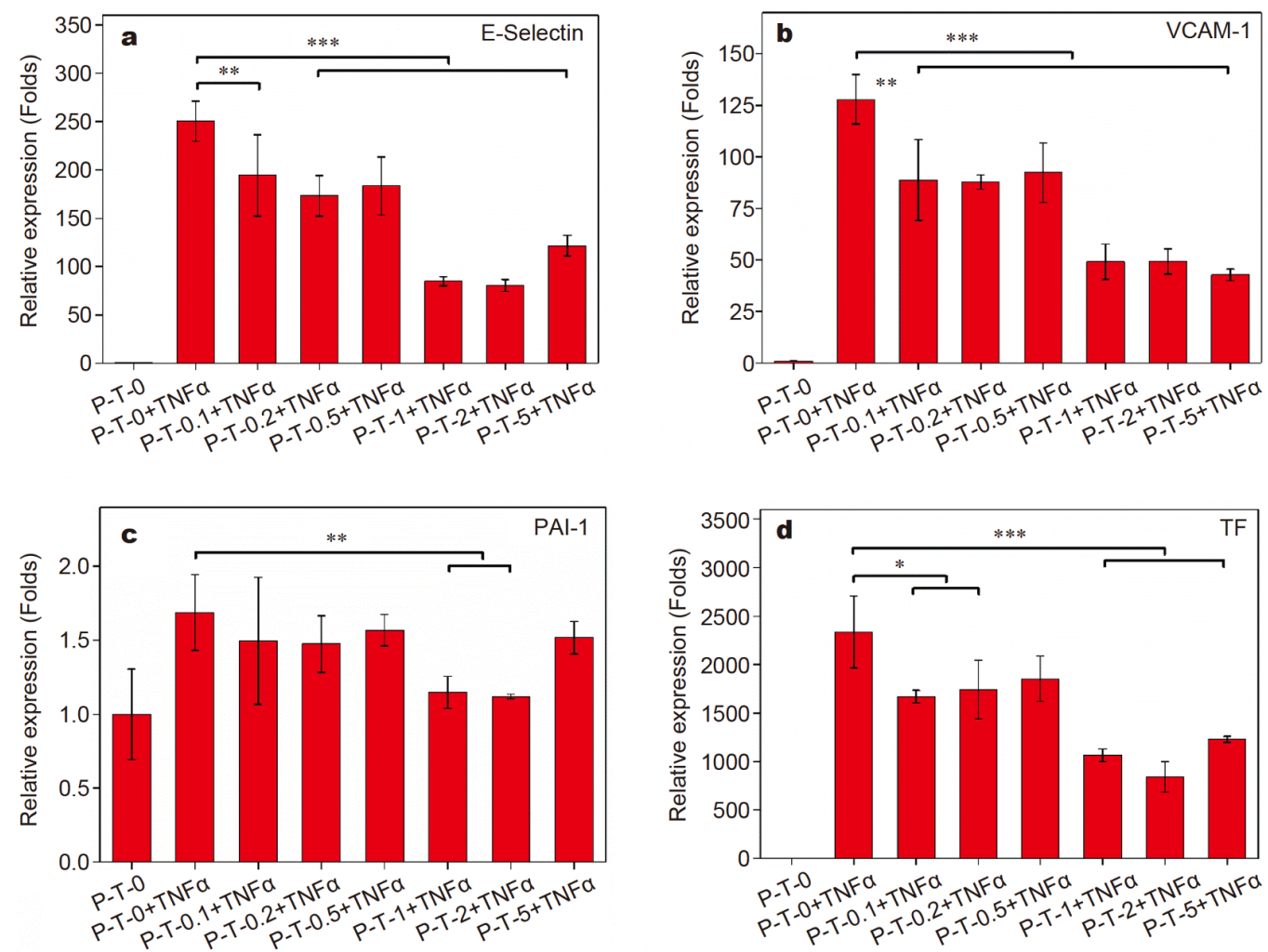

Figure 8 Inhibition of adhesive molecules and prothrombogenic factor expression in HUVECs by TEMPOL-loaded membranes. HUVECs were incubated with the samples for three days before a stimulation of TNFa for $2 \mathrm{~h}$. qRT-PCR analysis of (a) E-Selectin, (b) VCAM-1, (c) PAI-1 and (d) TF mRNA expression of HUVECs cultured on different samples. Data are presented as means $\pm \operatorname{SD}\left(n=3,{ }^{*} p<0.05,{ }^{* *} p<0.01\right.$, and $\left.{ }^{* * *} p<0.001\right)$.
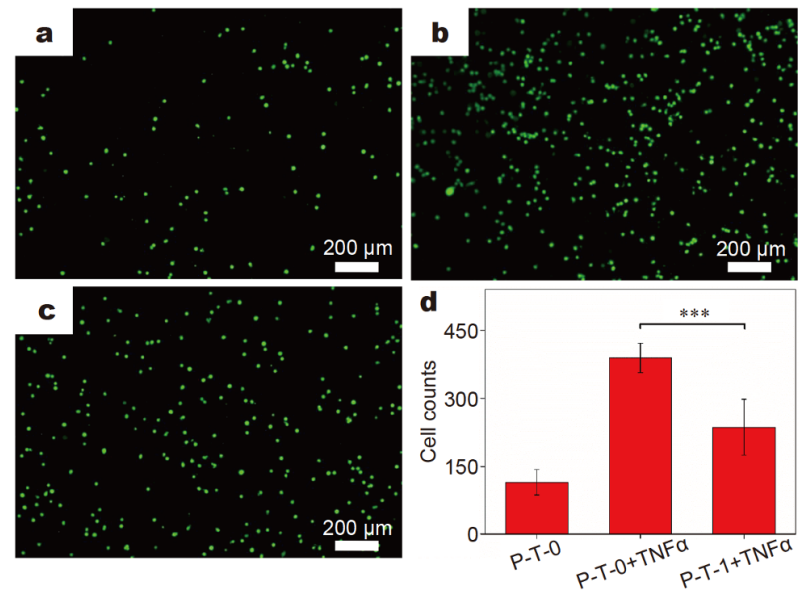

Figure 9 Inhibition of THP-1 monocytes adhesion onto the TEMPOLloaded membranes pre-incubated with HUVECs. HUVECs were incubated with the samples for three days before stimulated by TNFa for 2 h. Fluorescence images of adhered THP-1 cells: (a) without and (b) with TNFa stimulation on the control P-T-0 samples; and (c) with TNFa stimulation on P-T-1 sample; (d) quantitative analysis of adhered THP-1 cells. Data are presented as means $\pm \mathrm{SD}\left(n=5,{ }^{* * *} p<0.001\right)$.

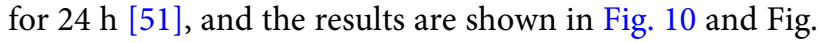
S7. Specifically, it is clearly shown that the migration of PDGF-BB-stimulated HASMCs was effectively inhibited on the P-T-1 membrane (i.e., P-T-1+PDGF-BB) at $16 \mathrm{~h}$ when compared with P-T-0 counterpart (i.e., P-T-0 + PDGF-BB). Such an inhibition effect was more apparent when observed at $24 \mathrm{~h}$ with about a $50 \%$ reduction of HASMCs migration (Fig. 10d). These results have well demonstrated that the TEMPOL-loaded electrospun membranes have the capability in counteracting the migration of cytokine-activated VSMCs.

\section{CONCLUSIONS}

In summary, we have successfully encapsulated TEMPOL into PDLLA nanofibers via a coaxial electrospinning process which provides the possibility for the topical release of antioxidants to scavenge ROS induced after the PCI therapy. Specifically, the actual loading amount of TEMPOL is tunable by simply changing the spinning concentration for the core layer; the PDLLA shell can also 

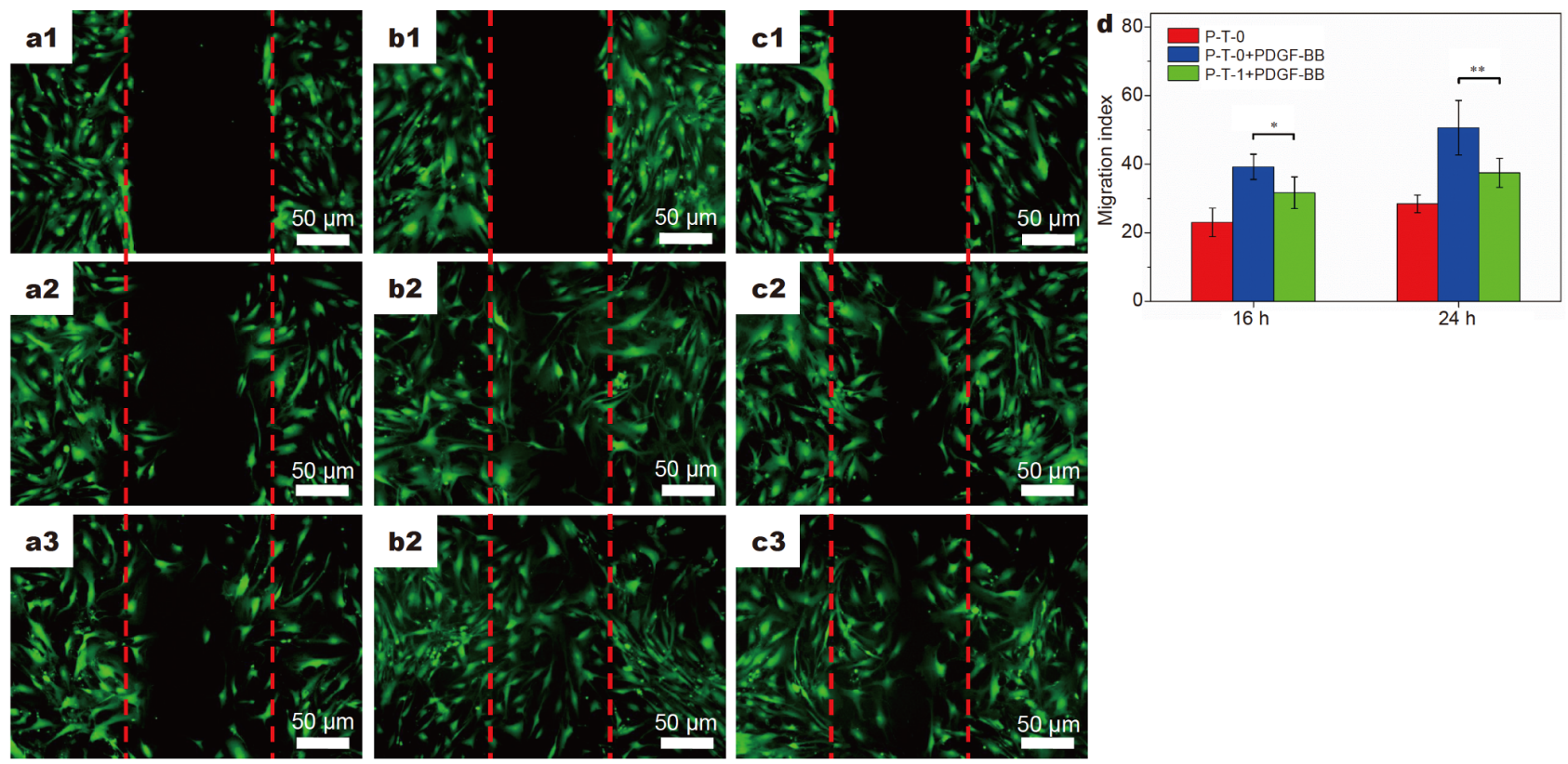

Figure 10 HASMCs migration under cultured different samples ((a) P-T-0 without PDGF-BB stimulation, (b) P-T-0 with PDGF-BB stimulation and (c) P-T-1 with PDGF-BB stimulation) at different times ((1) $0 \mathrm{~h}$, (2) $16 \mathrm{~h}$ and (3) $24 \mathrm{~h}$ ). (d) quantitative analysis of migration index. Data are presented as means $\pm \mathrm{SD}\left(n=5,{ }^{*} p<0.05,{ }^{* *} p<0.01\right)$.

serve as a protect layer for a long-term release of TEMPOL from the electrospun membranes. The in vitro performance indicated that the electrospun membranes with optimized TEMPOL loading amount (P-T-1) presented a good cytocompatibility with HUVECs, ROSscavenging and anti-inflammation performance in macrophages; it could also significantly attenuated adhesive molecules (e.g., VCAM-1, E-Selectin) and expression of prothrombogenic factors (e.g., TF, PAI-1) in HUVECs, the adhesion of THP-1 cells as well as the migration of HASMCs. Therefore, when used as coating on a stent for topically scavengering ROS, such a novel electrospun system has a great potential to address the restenosis and thrombosis issues after PCI therapy in practice.

Received 26 April 2020; accepted 29 June 2020;

published online 15 October 2020

1 Townsend N, Wilson L, Bhatnagar P, et al. Cardiovascular disease in Europe 2016: An epidemiological update. Eur Heart J, 2016, 37: 3182-3183

2 Roth GA, Johnson C, Abajobir A, et al. Global, regional, and national burden of cardiovascular diseases for 10 causes, 1990 to 2015. J Am College Cardiol, 2017, 70: 1-25

3 Holmes Jr DR, Taggart DP. Revascularization in stable coronary artery disease: A combined perspective from an interventional cardiologist and a cardiac surgeon. Eur Heart J, 2016, 37: 1873-1882

4 Zheng X, Curtis JP, Hu S, et al. Coronary catheterization and percutaneous coronary intervention in China. JAMA Intern Med,
2016, 176: 512-521

5 Piccolo R, Giustino G, Mehran R, et al. Stable coronary artery disease: Revascularisation and invasive strategies. Lancet, 2015, 386: 702-713

6 Kristensen MN, Frederiksen CA, Sivén E, et al. Negative inotropic and hypotensive effects of the superoxide dismutase mimetic tempol in pigs. Eur J Pharmacol, 2014, 731: 20-30

7 Polytarchou C, Papadimitriou E. Antioxidants inhibit human endothelial cell functions through down-regulation of endothelial nitric oxide synthase activity. Eur J Pharmacol, 2005, 510: 31-38

8 Tardif JC, Grégoire J, LAllier PL. Prevention of restenosis with antioxidants. Am J Cardiov Drugs, 2002, 2: 323-334

9 Juni RP, Duckers HJ, Vanhoutte PM, et al. Oxidative stress and pathological changes after coronary artery interventions. J Am College Cardiology, 2013, 61: 1471-1481

10 Wilcox CS. Effects of tempol and redox-cycling nitroxides in models of oxidative stress. Pharmacol Ther, 2010, 126: 119-145

11 Soule B, Hyodo F, Matsumoto K, et al. The chemistry and biology of nitroxide compounds. Free Radical Biol Med, 2007, 42: 1632-1650

12 Wilcox CS, Pearlman A. Chemistry and antihypertensive effects of tempol and other nitroxides. Pharmacol Rev, 2008, 60: 418-469

13 Saito K, Takeshita K, Ueda JI, et al. Two reaction sites of a spin label, tempol (4-hydroxy-2,2,6,6-tetramethylpiperidine- $N$-oxyl), with hydroxyl radical. J Pharm Sci, 2003, 92: 275-280

14 James EN, Delany AM, Nair LS. Post-transcriptional regulation in osteoblasts using localized delivery of miR-29a inhibitor from nanofibers to enhance extracellular matrix deposition. Acta Biomater, 2014, 10: 3571-3580

15 Chew S, Wen Y, Dzenis Y, et al. The role of electrospinning in the emerging field of nanomedicine. Curr Pharm Des, 2006, 12: 47514770

16 Huang W, Xiao Y, Shi X. Construction of electrospun organic/ 
inorganic hybrid nanofibers for drug delivery and tissue engineering applications. Adv Fiber Mater, 2019, 1: 32-45

17 Huang C, Wang S, Qiu L, et al. Heparin loading and pre-endothelialization in enhancing the patency rate of electrospun small-diameter vascular grafts in a canine model. ACS Appl Mater Interfaces, 2013, 5: 2220-2226

18 Lee $\mathrm{CH}$, Chang $\mathrm{SH}$, Lin $\mathrm{YH}$, et al. Acceleration of re-endothelialization and inhibition of neointimal formation using hybrid biodegradable nanofibrous rosuvastatin-loaded stents. Biomaterials, 2014, 35: 4417-4427

19 Qi R, Tian X, Guo R, et al. Controlled release of doxorubicin from electrospun MWCNTs/PLGA hybrid nanofibers. Chin J Polym Sci, 2016, 34: 1047-1059

20 Yang Y, Lei D, Zou H, et al. Hybrid electrospun rapamycin-loaded small-diameter decellularized vascular grafts effectively inhibit intimal hyperplasia. Acta Biomater, 2019, 97: 321-332

21 Zhang Y, Fang Q, Niu K, et al. Time-dependently slow-released multiple-drug eluting external sheath for efficient long-term inhibition of saphenous vein graft failure. J Control Release, 2019, 293: $172-182$

22 Han F, Jia X, Dai D, et al. Performance of a multilayered smalldiameter vascular scaffold dual-loaded with VEGF and PDGF. Biomaterials, 2013, 34: 7302-7313

23 Zhang H, Jia X, Han F, et al. Dual-delivery of VEGF and PDGF by double-layered electrospun membranes for blood vessel regeneration. Biomaterials, 2013, 34: 2202-2212

24 Ardila DC, Tamimi E, Doetschman T, et al. Modulating smooth muscle cell response by the release of TGF $\beta 2$ from tubular scaffolds for vascular tissue engineering. J Control Release, 2019, 299: 44-52

25 Guo HF, Dai WW, Qian DH, et al. A simply prepared smalldiameter artificial blood vessel that promotes in situ endothelialization. Acta Biomater, 2017, 54: 107-116

26 Chung HJ, Kim JT, Kim HJ, et al. Epicardial delivery of VEGF and cardiac stem cells guided by 3-dimensional PLLA mat enhancing cardiac regeneration and angiogenesis in acute myocardial infarction. J Control Release, 2015, 205: 218-230

27 Zhou F, Jia X, Yang Y, et al. Nanofiber-mediated microrna-126 delivery to vascular endothelial cells for blood vessel regeneration. Acta Biomater, 2016, 43: 303-313

28 Zhu Y, Matsumura Y, Velayutham M, et al. Reactive oxygen species scavenging with a biodegradable, thermally responsive hydrogel compatible with soft tissue injection. Biomaterials, 2018, 177: 98-112

29 Ishii S, Kaneko J, Nagasaki Y. Dual stimuli-responsive redox-active injectable gel by polyion complex based flower micelles for biomedical applications. Macromolecules, 2015, 48: 3088-3094

30 Li G, Chen Y, Cai Z, et al. 5-Fluorouracil-loaded poly- $L$-lactide fibrous membrane for the prevention of intestinal stent restenosis. J Mater Sci, 2013, 48: 6186-6193

31 Oh B, Lee $\mathrm{CH}$. Advanced cardiovascular stent coated with nanofiber. Mol Pharm, 2013, 10: 4432-4442

32 Jagadeesha DK, Miller, Jr. FJ, Bhalla RC. Inhibition of apoptotic signaling and neointimal hyperplasia by tempol and nitric oxide synthase following vascular injury. J Vasc Res, 2009, 46: 109-118

33 Onuma S, Nakanishi K. Superoxide dismustase mimetic tempol decreases blood pressure by increasing renal medullary blood flow in hyperinsulinemic-hypertensive rats. Metabolism, 2004, 53: 1305-1308

34 Yoshitomi T, Miyamoto D, Nagasaki Y. Design of core-shell-type nanoparticles carrying stable radicals in the core. Biomacromolecules, 2009, 10: 596-601
35 Li L, Guo J, Wang Y, et al. A broad-spectrum ros-eliminating material for prevention of inflammation and drug-induced organ toxicity. Adv Sci, 2018, 5: 1800781

36 Zamani M, Morshed M, Varshosaz J, et al. Controlled release of metronidazole benzoate from poly $\varepsilon$-caprolactone electrospun nanofibers for periodontal diseases. Eur J Pharm Biopharm, 2010, 75: $179-185$

37 Repanas A, Glasmacher B. Dipyridamole embedded in polycaprolactone fibers prepared by coaxial electrospinning as a novel drug delivery system. J Drug Deliver Sci Tech, 2015, 29: 132-142

38 Yin A, Luo R, Li J, et al. Coaxial electrospinning multicomponent functional controlled-release vascular graft: Optimization of graft properties. Colloids Surfs B-Biointerfaces, 2017, 152: 432-439

39 Peppas NA. Analysis of fickian and non-fickian drug release from polymers. Pharm Acta Helv, 1985, 60: 110-111

40 Yuan Y, Mu R J, Yang D, et al. Konjac glucomannan/poly(vinyl alcohol) nanofiber film and its drug release behavior. Acta Polym Sin, 2017, 3: 498-505

41 Liu X, Yang Y, Yu DG, et al. Tunable zero-order drug delivery systems created by modified triaxial electrospinning. Chem Eng J, 2019, 356: 886-894

42 Gbureck U, Vorndran E, Barralet JE. Modeling vancomycin release kinetics from microporous calcium phosphate ceramics comparing static and dynamic immersion conditions. Acta Biomater, 2008, 4: 1480-1486

43 Gutierrez J, Ballinger SW, Darley-Usmar VM, et al. Free radicals, mitochondria, and oxidized lipids. Circ Res, 2006, 99: 924-932

44 Jaipersad AS, Lip GYH, Silverman S, et al. The role of monocytes in angiogenesis and atherosclerosis. J Am College Cardiology, 2014, 63: 1-11

45 Mittal M, Siddiqui MR, Tran K, et al. Reactive oxygen species in inflammation and tissue injury. Antioxid Redox Signal, 2014, 20: 1126-1167

46 Wang Y, Li L, Zhao W, et al. Targeted therapy of atherosclerosis by a broad-spectrum reactive oxygen species scavenging nanoparticle with intrinsic anti-inflammatory activity. ACS Nano, 2018, 12: 8943-8960

47 Piatti PM, Monti LD. Insulin resistance, hyperleptinemia and endothelial dysfunction in coronary restenosis. Curr Opin Pharmacol, 2005, 5: 160-164

48 Kern MJ. Persistent endothelial dysfunction after drug-eluting stents. JACC-Cardiov Intervent, 2008, 1: 72-73

49 Sakamoto A, Jinnouchi H, Torii S, et al. Understanding the impact of stent and scaffold material and strut design on coronary artery thrombosis from the basic and clinical points of view. Bioengineering, 2018, 5: 71

50 Kornowski R, Hong MK, Tio FO, et al. In-stent restenosis: Contributions of inflammatory responses and arterial injury to neointimal hyperplasia. J Am College Cardiol, 1998, 31: 224-230

51 Shawky NM, Segar L. Sulforaphane inhibits platelet-derived growth factor-induced vascular smooth muscle cell proliferation by targeting mTOR/p70S6kinase signaling independent of NRF2 activation. Pharmacol Res, 2017, 119: 251-264

Acknowledgements This work was supported by the National Key Research and Development Program of China (2016YFA0201702 and 2016YFA0201700), the National Natural Science Foundation of China (51733002, 81670319 and 81521001), the Fundamental Research Funds for the Central Universities (19D110618), the Overseas Expertise Introduction Project for Discipline Innovation (111-2-04), and the Chinese Academy of Medical Sciences' Innovation Fund for Medical Sciences 
(CAMS, 2019-I2M-5-060).

Author contributions Zhu M, Ge J and Fei X designed the experiments. Lu J, Wang R, and Shen L performed the experiments. Lu J, Wang R, Shen L, and Fei X analyzed the data. Lu J, Wang R, Shen L and Fei X wrote the manuscript. Liu G, Chen $\mathrm{H}, \mathrm{Xu} F, \mathrm{Wu} \mathrm{Q}$ and Ye C contributed materials and analysis tools. All authors revised the manuscript.

Conflict of interest The authors declare that they have no conflict of interest.

Supplementary information Experimental details and supporting data are available in the online version of the paper.

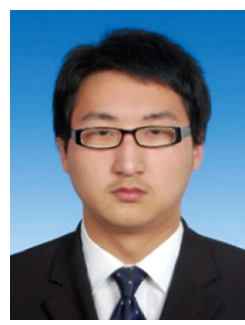

Jian Lu is a $\mathrm{PhD}$ student in the College of Material Science and Engineering \& State Key Laboratory for Modification of Chemical Fibers and Polymer Materials (SKLFPM) at Donghua University. His research focuses on the preparation and biological applications of fiber materials.

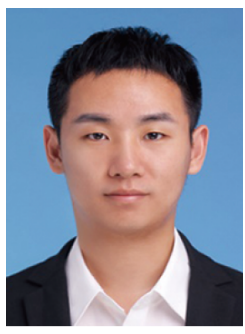

Rui Wang is a $\mathrm{MD}$ and $\mathrm{PhD}$ candidate of Shanghai Institute of Cardiovascular Diseases at Fudan University. He engaged in researches of several cardiac interventional products (bioresorbable polymeric PLLA scaffold XINSORB, etc.). His research focuses on the mechanism of vascular remodeling following devices implantation.

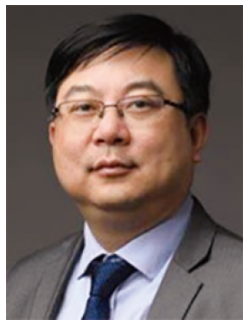

Li Shen, MD, Fellow of the American College of Cardiology (FACC), is working at the Department of Cardiology, Zhongshan Hospital, Fudan University. $\mathrm{He}$ is a supervisor of postgraduate, associate professor, chief physician; Youth member of Chinese Society of Cardiology, secretary-general of the Center for Cardiovascular Innovation, deputy director of Engineering $\mathrm{Re}$ search Center for Cardiovascular Devices, Ministry of Education (ERCCD, MOE), and secretary-general of Cardiovascular Intervention Branch of China Association for Medical Devices Industry. Dr. Shen participated in research and development of several cardiac interventional products (arsenic trioxide eluting stent, first bioresorbable polymeric PLLA scaffold in China-XINSORB, world's first deep freeze renal nerve ablation catheter-CryoFocus, etc.).

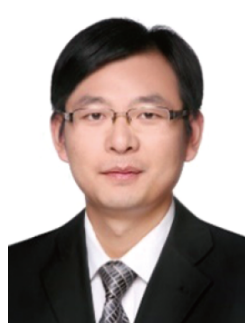

Xiang Fei is an assistant professor in the College of Material Science and Engineering \& SKLFPM at Donghua University. He obtained his $\mathrm{PhD}$ from Fudan University (2013). Prior to joining Donghua University, he worked as a postdoctoral fellow at the University of Zurich (2013-2016) and as a research fellow at the National University of Singapore (2016-2018). His research focuses on rational design and preparation of smart polymer fibers and fabrics.

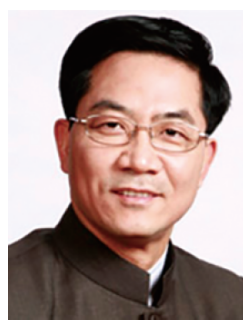

Junbo Ge is a professor, doctoral tutor and academician of Chinese Academy of Sciences. He received a $\mathrm{PhD}$ degree in medicine from Mainz University, Germany, in 1993. He is the president of Chinese College of Cardiovascular Physicians; the chairman of China Cardiovascular Association; the chief of the Cardiology Department of Zhongshan Hospital, Fudan University; the chairman of Shanghai Institute of Cardiovascular Diseases; board member of World Heart Federation (WHF). Prof. Ge has been engaged in the clinical work and scientific research of cardiology since 1987. He dedicates to the optimization and innovation of diagnosis and treatment strategy for coronary artery disease and made extraordinary achievements in intravascular ultrasound (IVUS), development of novel coronary stents, intervention strategy of complex CAD and the cell therapy, etc.

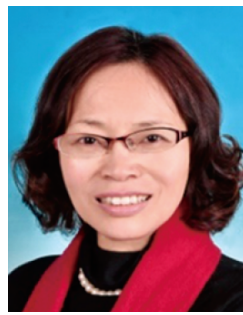

Meifang Zhu is the dean of the College of Material Science and Engineering, and the director of SKLFPM at Donghua University. She graduated from the Department of Chemical Fiber of China Textile University in 1986, and got the master's degree of chemical fiber in 1989 and the $\mathrm{PhD}$ degree of materials in 1999. She was a lecturer and an associate professor in the Department of Polymer Materials at China Textile University from 1989 to 1999 and has been a professor of the College of Materials Science and Engineering in Donghua University since 1998. Her research fields mainly focus on polymer fiber and nanocomposite functional materials, application and key technology research of organic/inorganic nano hybrid materials.

负载TEMPOL的静电纺丝纳米纤维实现PCI相关 并发症治疗的局部长期抗自由基性能

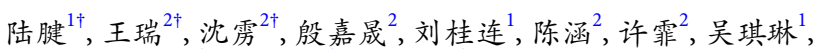
叶长怀 ${ }^{1}$, 费翔 ${ }^{1 *}$, 葛均波 ${ }^{2 *}$, 朱美芳 ${ }^{1 *}$

摘要 使用抗氧剂清除活性氧(ROS)被证实是应对经皮冠状动脉介 入治疗 (PCI) 相关并发症的有效方法, 但抗氧剂向特定组织的长期 局部输送不易实现. 本文将抗氧剂TEMPOL可控地负载入静电纺 丝纳米纤维以实现其局部应用和长期抗自由基能力, 制得 TEMPOL负载薄膜的生物功能通过细胞增殖、ROS清除能力、单核细 胞黏附、细胞迁移、炎症因子 mRNA水平的表达及分泌等体外实 验进行了表征. 薄膜在优化TEMPOL负载量后, 对内皮细胞和巨噬 细胞表现出优异的清除ROS和抗炎症能力; 同时有效抑制内皮细胞 促血栓形成因子的表达和血管平滑肌细胞的迁移. 因此, 我们预测 该TEMPOL负载电纺体系的局部使用，如用作长期局部输送抗氧 化药物的血管支架涂层, 可以有效治疗血管再狭窄和抑制血栓形 成. 